

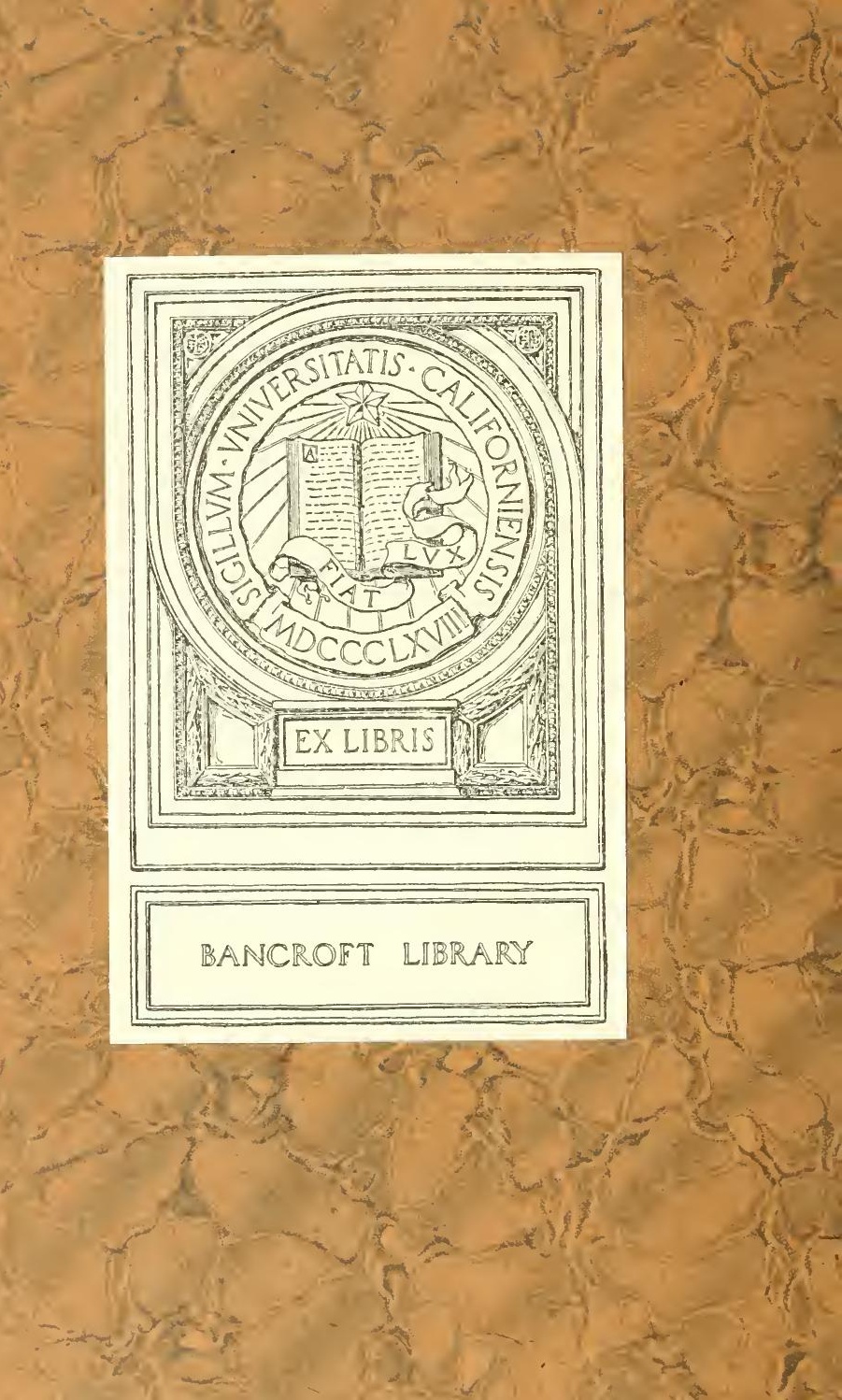




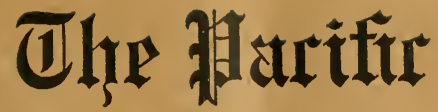

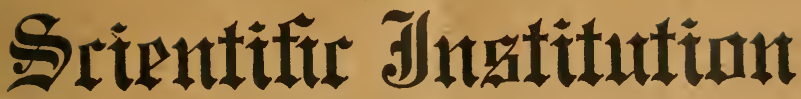 \\ AN ADDRESS BY \\ WILLIAM ALANSON BRYAN}



Sprial Seripr

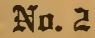

CHICAGO, ILL., JANUARY

NINETEEN HUNDRED AND EIOHT 

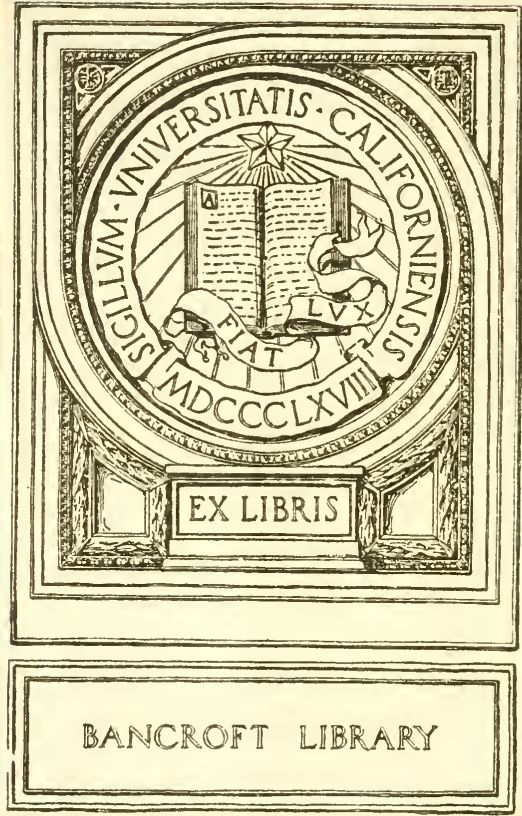


\title{
THE PACIFIC
}

\section{SCIENTIFIC INSTITUTION}

\author{
AN ADDRESS BY \\ WILLIAM ALANSON BRYAN \\ Pacific Institution Publications \\ Special Series \\ No. 2
}


Digitized by the Internet Archive in 2008 with funding from Microsoft Corporation 


\section{THE PACIFIC SCIENTIFIC INSTITUTION ${ }^{\mathrm{T}}$}

By William Alanson Bryan

Contents.-(I) A General Statement; (2) The Pacific Institution; (3) The Exploring Expedition; (4) General Administration of the Institution; (5) The Scientific Organization of the Institution; (6) Scope of the Inquiry; (7) Departments of the Institution; (8) Disposition of the Material; (9) Publications.

\section{A GENERAL STATEMENT}

So far as the demands of modern science are concerned, the Pacific Ocean is still little less than a vast unexplored realm. The best authorities agree that the region is literally teeming with a wealth of raw material for study in every department of scientific research. This is true in spite of the fact that since the days of Cook's memorable voyages of discovery there has scarcely been an ethnologist, a geologist, a zoölogist, or a botanist worthy of the name, who has not longed to explore the region; or whose mind and heart have not been enthralled at the very thought of the virgin opportunity for original research awaiting any investigator who will study the problems of science involved in the Pacific's vast watery domain.

Indeed, to explore exhaustively the region; to fathom its unknown depths; to delve into its great mysteries; to study at first hand its people, its fauna, and its flora, have all been among the dearest ambitions of men of science the world over.

Although appreciating fully, the opportunity for scientific achievements offered in particular lines of investigation fewindeed, very few-of even the best informed of men have ever conceived in more than a vague way of the enormous sum total of scientific work still remaining to be done in the Pacific Ocean. Yet the veriest tyro knows well that there are scores of islands scattered over this broad expanse on which scientists have never even set

I An address delivered by the president of the Institution before the Chicago meeting of the American Association for the Advancement of Science, December 30, 1907 . 
foot. It is not strange, therefore, that romances, adventures, explorers, scientists, one and all have dreamed fond dreams of some day plundering for one reason or another, in some way or other, this great storehouse of knowledge, adventure, and discovery.

In moments of reckless fancy many such dreams of conquest have been made over into tentative plans for accomplishing what is without doubt the world's greatest task of exploration. Unfortunately many of the plans thus proposed, though worthy in themselves, have been doomed from the first to languish for want of financial support, or worse still have perished from lack of the ordinary encouragement which one enthusiast is usually willing to accord to another.

In view of the many disappointments of the past it is gratifying and significant to find that the effort now being made to form a thoroughly modern co-operative scientific institution with the endowment and facilities necessary to carry on rapidly an exhaustive survey of the whole region is everywhere being received with the most cordial approval and support. At last one of the many plans of exploration that has been offered is to be brought to fruition. Hawaii, situated in the midst of the region to be studied is to be the center of this great undertaking.

The propriety of Honolulu serving as a focal point and leading in the work, as well as the fact that at last a worthy survey of the Pacific is to be inaugurated has been hailed by men in all countries, both in and out of science, with the utmost enthusiasm. For there are many who believe that the results growing out of a carefully planned and faithfully executed exploration of the whole realm will add more to the sum of human knowledge than any single effort of a like kind that can be attempted.

It seems unnecessary to discuss the many urgent reasons which make the exploration of this region almost imperative. Everyone knows that the Polynesian race is not only passing away, but that it is taking with it into the great beyond all the facts which would elucidate the manifold problems involved in the origin and subsequent distribution of the various branches of the race in the Pacific. We know that the civilization of the Polynesian people was not only very old at the time of their discovery by the white 
race, but, considering the circumstances of isolation under which the race was developed, very far advanced. Yet farther than the meager records of early explorers and the narratives of traders, missionaries, and adventurers, all of whom in their writings treated the civilization of the natives in a superficial manner, we know next to nothing of one of the great races of mankind. Ethnologists yearn for reliable knowledge of this interesting-yes, fascinating people. They assert that we must ascertain their origin, tribal traditions, and social affinities before a worthy history of the human race can be written. We all know too well of the rapid change of conditions and the obliteration of the facts upon which the study of any primitive people depends. Anyone at all familiar with the peculiar conditions in the Pacific feels that with the Polynesian and kindred tribes it is indeed now or never that this work must be done.

That which is true of the Polynesian race as a people is equally true of the material in every department of natural history. That which it is so important to preserve or record is everywhere passing away or changing in character. Then too, an exhaustive examination of any one subject in the Pacific is so interwoven with others, that the study of the one is remarkably involved by the lack of knowledge of the other. This is true to such an extent that in order to be of a high character, any ethnological survey of the region requires as a starting-point information which is today sadly lacking of the oceanology, climatology, geology, zoölogy, and botany of the entire ocean.

A task which involves so much exploration, investigation, and research can only be accomplished by creating first of all a scientific center exclusively devoted to this especial work. Such a center must undertake to collect and bring thither all of the material and data on which the investigation must be based. It must then provide the men and facilities necessary for the study of the material, once it is assembled, and lastly, in order to make the labor of the survey permanent and valuable, ample opportunity for the publication and application of the facts thus obtained must be provided. Thus the results of the undertaking may be permanently added to the general store of human knowledge for the benefit and improvement of all. 
Until recently the Pacific has been regarded as so remote from the old and well-established centers of civilization and learning that many have felt that it would be difficult, if not impossible, to carry out such an undertaking as is here proposed. Happily that objection is now removed and the desirability of Honolulu serving as the center for the work is generally admitted.

Honolulu, the capital of Hawaii, is a thoroughly modern city. It is equipped with every modern convenience, being supplied with abundant cable and steamship connections, with all parts of the Pacific. It has the most delightful and healthful climate in the world, and in addition to its many widely recognized scientific and educational facilities, offers natural advantages pre-eminently fitting it to lead in this work - a work which is in truth a "world's work" in scope and significance.

Besides the remoteness of the Pacific from established centers of learning as just alluded to, there have been innumerable reasons for delay in undertaking this great task. Aside from the lack of sufficient funds the chief and most important cause of delay in the past has been that the islands of the region are divided among the nations of the earth in such a way that no country has been ready or willing to incur the expense incidental to the exploration and charting of a sister country's domain. As a result, the little that has been accomplished by home governments or private enterprise has been desultory, fragmentary, and in a large degree futile, from lack of scope and consistent purpose.

It therefore remained for some individual or institution or association of individuals and institutions to take up and, so far as possible, carry forward the undertaking, and by so doing do for the world a work that the state or nation could not legitimately attempt.

Such, then, briefly told, are some of the purposes of and reasons for the existence of the Pacific Scientific Institution, with the organization, purposes, and work of which it is the province of this paper to deal.

\section{THE PACIFIC SCIENTIFIC INSTITUTION}

In order to carry on in a comprehensive way the administrative and resident research work of the exploration of the region and at the same time provide for the inevitable lateral expansion of such 
an undertaking, the Pacific Scientific Institution has been formed. It is a corporation under the control of an especial honorary board of fifteen trustees, who are empowered to receive, in trust, funds, property, or equipment for the prosecution, promotion, and maintenance of scientific research in the Pacific Ocean. The main object of the trust, as set forth in the charter, is the effecting of a thorough biological and ethnological survey of the Pacific. In addition to other liberal powers, the trustees are given discretion to wind up their affairs, when in their judgment the main object for which the trust is created shall have been completed. They will, in that event, make such a disposition of the trust funds as may have been provided for by the benefactors, or in default of such instructions, as they themselves may, within limitations, determine. ${ }^{I}$ They are also empowered to reorganize, endow, and permanently establish any one or all of the especial institutions which may be created by them for the continuance of research in the Pacific.

As the means appear, the trustees will establish central offices of administration in Honolulu provided with laboratories, libraries, printing equipment, etc., which they will house in buildings of a more or less temporary character. They will also, as speedily as possible, establish a biological station, an aviary or zoölogical garden, a garden of acclimatization or botanical garden, and such other scientific institutions or facilities as they may in future deem desirable. ${ }^{2}$ When practicable, the Pacific Scientific Institution will affiliate with the various scientific and educational institutions already well established in Hawaii, such as the Honolulu Aquarium, the Historical Library, the Bernice Pauahi Bishop Museum, Oahu College, Hawaiian Experiment Station, and similar institutions, with the object of forming a local research institution with adequate facilities for prosecuting, in the fullest and most satisfactory way, a work of the extent and character indicated in the general plan of exploration.

The Peabody fund for the promotion of education in the South is cited as a strong precedent case.

2 In this connection I am happy to say that provision has already been made for the establishment of the three important scientific centers just mentioned, through the munificence of interested patrons in Honolulu. 
To facilitate the research work from time to time, additional tables of research under the control of the Institution will be endowed, which will be provided by patrons and interested institutions in such a way that the Pacific Scientific Institution can call to its assistance a corps of specialists, as they are required, to work on the problems with which the survey is to deal, and at the same time to furnish specialists in the old well-established museums and universities much needed opportunity for colateral research in the Pacific insular province.

This, it is confidently believed, will promote a spirit of co-operation among the universities, museums, and scientific institutions of the world, that are directly or indirectly interested in a study of the Pacific, which will be most helpful and desirable in every way.

\section{THE EXPLORING EXPEDITION}

The present plan for field work is to acquire an especially equipped yacht of from five to seven hundred tons capacity, which will be provided with sails as well as oil-burning engines, and fitted with the necessary accommodations for fifteen scientific men, including laboratories, field library, storage tanks, etc.

This vessel, using Honolulu as a base, and establishing secondary focal points from which to carry on its work, will make cruises to the various groups of islands in the Pacific region. The voyages can be so arranged that the entire ocean, with its more than two thousand islands, may be thoroughly covered in about fifteen excursions. Thus the vast region would be worked over, group by group, with a fully equipped corps of especially trained field scientists; the time required to complete the work, of course, varying with the number and size of the parties in the field. In this way the work and publications on any group, as for example on the Society Islands, would be uniform and complete; every department of ethnology and natural history will be treated, both in the field and in the subsequent publication, by a specialist. By reason of a carefully prearranged plan, the study of each island will be made with an understanding of the great ultimate object, namely, knowledge of the Pacific Ocean as a whole. The data thus gathered will always be even and of a comparable character. 
The central institution in Honolulu will in due time affiliate with the various universities and museums of the world in a way to offer an opportunity for actual field work to the graduate students of those institutions. The undertaking will thus be supplied with a constantly increasing corps of young and enthusiastic naturalists for the arduous work of the field exploration. They will bring with them to the work the support of their especial institutions; since their appointments on the expeditions will be gained, in the main, through meritorious work done during their preparatory courses. It is evident that work of this character is not only supplementary to the university and museum training, but that such expeditions will furnish scientific employment for many graduates of our colleges and universities along the line of their especial training. It will also provide a means of doing postgraduate work under remuneration during the critical time between leaving college and the finding of satisfactory or permanent employment in scientific pursuits. On the other hand, the expeditions will be carried on at a minimum of expense, while offering splendid facilities for the development of scientific men, from among whom the Institution will select its permanent staff as the work of the survey advances.

\section{GENERAL ADMINISTRATION OF THE INSTITUTION}

A simple and, it is believed, workable plan that is adapted to the character of the work the Institution is to carry on has been adopted for the general administration of the affairs of the Institution.

A board of fifteen trustees has been appointed. The board is composed of men of highest business, judicial, or educational standing in the Hawaiian Islands. Since they reside in Honolulu, they are intimately in touch with the work of the Institution at all times. They serve without remuneration other than the expenses incidental to the administration of the trust funds. This body has the general and complete control of the affairs of the corporate Institution. However, if it seems wise, they may obligate the Institution to make annually a comprehensive statement of its general affairs or the affairs of any special department of the work under 
their control to any person or corporation which a donor may designate to receive such reports.

The trustees meet at stated intervals for a review of the affairs of the Institution, and to hear and act on the president's monthly or quarterly reports. The board is organized into various committees, which are empowered to act for the full board in certain matters in order to facilitate its business.

The president is the chief executive officer of the Institution, and is ex officio a member of the Board of Trustees, serving during the pleasure of the board. The Executive Committee is composed of the five officers of the Institution, as recognized by the charter of incorporation and has general control of the affairs of the Institution when the trustees are not in session.

Each department under the direct control of the Pacific Scientific Institution will have its responsible officer styled the Director. The by-laws provide that he shall make his reports and be responsible to the president of the Institution.

Institutions affiliated with the Pacific Scientific Institution will be addressed and recognized through the Institution's proper representative; affiliation being effected by both institutions concerned, accepting written conditions of such alliance.

\section{THE SCIENTIFIC ORGANIZATION OF THE INSTITUTION}

The president is directed to select an Honorary Scientific Council consisting of gentlemen who are of international reputation in scientific and educational matters.

With the assistance and advice of the Honorary Scientific Council the details of the systematic work will be so arranged that a definite system of procedure will be settled upon before the actual exploration is inaugurated. The members of the Scientific Council will assist as advisers in the selection of the leading specialists who shall serve as curators of the several more or less limited departments into which the scientific work will necessarily be divided. The gentlemen thus selected will serve as the honorary curators of the departments in which they have distinguished themselves, and will exercise a general advisory supervision over the work, material, and publications of their especial departments. When possible 
they will be consulted in the selection of the curators, assistants, and collectors who shall work in their respective departments, and will be regarded as forming the heads of departments of the scientific staff.

One of their first duties will be to prepare for the Institution a full and comprehensive statement of the status of their specialty, with reference to the Pacific Ocean. In their reports they will treat as fully as circumstances will allow such subjects as the regions in which collections have been made-regions from which no satisfactory collections have been secured-the kind and quantity of the material required; equipment necessary for the collecting, storing, and study of the material; a list of the important literature dealing with their specialty in the region; the kind, quantity, and form of field notes to be collected; the lines along which investigation should be pursued; theories which require further or more minute study afield or in the laboratories, etc.

These theses will be collected, edited, and eventually published to furnish the broad foundation on which the survey will be conducted. Such a book will serve the young student as a touchstone; and will be a guide to what has been accomplished in the past and what yet remains to be done. It will be a source of inspiration, tending to make the material, gathered from any source, in the various groups, by various observers, take on a more even and comparable character.

\section{SCOPE OF THE INQUIRY}

As has been intimated, perhaps none of the many subjects which require immediate investigation in this vast region are of greater importance than those with which ethnology deals. Haphazard and promiscuously gathered specimens, regarded as mere curios by the voyagers, have furnished a large proportion of the ethnological material that has gravitated to our museums. Without data, often without labels, it has been assigned by different workers to different islands, until its value, even as curios, has disappeared. Yet such specimens are all faithfully guarded by museum custodians in the hope that competent and properly trained ethnological explorers with modern methods may yet go afield and 
locate the place of their origin and supply the data that will make them priceless. Indeed, the ethnology of the region is so imperfectly known, that the few workers in the field are often at a loss to know what line of work is the most urgent to pursue; so great and manifest are the gaps in our scientific knowledge of this interesting race. As has been said, the rapid changes which civilization and commerce are effecting will soon obliterate all that remains of the native culture of this people.

Therefore the main work of the expeditions will be to study the races of man inhabiting the Pacific, in a manner similar to that in which the Bureau of American Ethnology has studied the American Indian. Such a study should cover their physical, mental, linguistic, social, religious, aesthetic, and industrial development, as well as the problems of race mixture and the causes of racial decay among the primitive tribes inhabiting the multitude of Pacific islands. Since the material for the elucidation of many of the problems involved does not exist in any museum or museums, exhaustive collections must be made, both in the field and by purchase, which will illustrate their crafts before it is too late to secure them.

Next in importance is the study of land biology. The limited size of the majority of the islands makes the extermination of existing peculiar forms a matter speedily accomplished by the introduction of foreign plants and animals, or unusual conditions. For example, among the birds on the island of Oahu the number of species known to science which have been exterminated since their description exceeds those now existing on the island. Still in the Pacific there remain many islands unexplored by scientists and thousands of forms of animal life that are as yet undescribed.

In the plant world similar conditions exist. There are hundreds of species which are unknown; while the geographical extent, abundance, variation, native names, and economic uses of all the plants of the region must be investigated and recorded. Such a survey will, without doubt, aid materially in the development and utilization of the botanical resources of the tropical islands of the world.

The value of the study of the shore fauna and flora cannot be 
exaggerated. To illustrate: the marine life of the Hawaiian Islands is better known than that of any group in the region that it is proposed to visit; yet the U. S. Fish Commission, in a brief season's collecting, secured more than one hundred and fifty new species in the waters about the islands. Still we know more about fishes than we do of any of the many other marine forms of life.

The work of Dr. T. Wayland Vaughn on the corals of Hawaii revealed the fragmentary nature of our knowledge of this important subject. The researches of Dr. Walter K. Fisher on the Hawaiian Holothuroidea furnishes even more convincing evidence along the same line. In his excellent monograph he describes sixty species of that class as occurring about the Hawaiian Islands, fifty-two of which are reported as new to science. Indeed the possibilities of a careful investigation of the coast fauna and flora, down to the limit of the effect of light on ocean forms, can scarcely be conceived.

\section{DEPARTMENTS OF THE INSTITUTION}

In order to facilitate the exhaustive study of the life history and economic importance of both plants and animals, the establishment of the biological station, an aviary, and a botanical garden in Honolulu are made to take a prominent part in the general scheme.

These have all received financial support and will be established from time to time by the central institution as supplemental to its work, and will so far as possible be made the center for the work of the Institution in the particular field which they cover. One of the most important will be the Botanical Garden and Tropical Gardens of Acclimatization in which will be grown and studied many of the important plants procured by the Institution's explorers. The production of new and important tropical fruits, flowers, and other economic plants from plants thus introduced will be an important branch of the Institution's applied botanical work.

The unrivaled situation of the Hawaiian Islands with the diversity of climate which can be obtained in the various altitudes available, should in time make this one of the world's most important and beautiful botanical gardens.

An aviary will be provided that will partake of the nature of 
zoölogical gardens for the reception of the birds and animals of the Pacific. Here the rare and beautiful birds of the region will be brought and studied, as the results of the survey are procured. The systematic and economic study of birds will be the major work of this department of the Institution. The economic study of birds is as yet almost an untrodden field of practical research. The far-reaching value of investigation in this branch of the work can scarcely be estimated.

The Honolulu Aquarium is an institution of which the island city is justly proud. The addition of rare varieties of fish to its tanks, will, without doubt, make possible in time the bringing together in the three institutions mentioned one of the most complete living collections of the plant and animal life of a single region to be found anywhere on the globe.

The study of the marine botany and zoölogy will also be actively pursued. The first department of the work to receive financial support from one of Hawaii's generous citizens was the Biological Station. In its laboratories the work in general and experimental biology growing out of the survey will be carried on. In it, as well as in the general institution, will be endowed tables of research to which we are assured scientific men will resort from all parts of the world. Work in the biological laboratory, where the simpler forms of plant and animal can be exhaustively studied, has come to be regarded as one of the most fruitful sources of research. Many biologists believe that the laboratory is the workshop where the answer to the old, old question as to the "origin of life" is being forged. Who knows but that it may fall to Hawaii to provide for the world the means and material with which to elucidate this great riddle. It will be remembered by all that the great Pacific in times passed furnished much of the fresh data and material, which in the hands of such philosophers as Darwin, Wallace, and Gulick gave a solution for many of the most difficult problems in evolution.

DISPOSITION OF THE MATERIAL

It is urged that the Bcrnice Pauahi Bishop Museum, by reason of its central location within the region to be studied, be made the 
principal recipient and final depository of the first series of the material to be gathered by the survey. The general accessibility of the museum to students residing on the shores of the great ocean, coupled with the nature and value of the collections already permanently stored within its halls, no less than the important part that the museum will doubtless take in the work of exploration, are among the many points that might be urged in favor of such a disposition of the type material.

However, the final disposition of the material in the Bishop Museum, after it has been worked out by the Institution, would seem to be a matter for treaty, conditioned among other things on the museum's early and helpful affiliation with the Pacific Scientific Institution. Also some definite expression of the museum's willingness to make the necessary provisions for the permanent storing, exhibition, and conservation of the material that would fall to its share by this arrangement would be necessary. In order to make the material gathered accessible to workers in all parts of the world it is suggested that the U. S. National Museum be made the recipient of the second set of material. The third set of specimens should be distributed among the leading specialists actually engaged in the systematic work. It would invariably gravitate by bequest or purchase to the institution most interested in the specialty in question.

\section{PUBLICATION OF THE INSTITUTION}

The publication of the results of such an exploration as has been outlined in the preceding pages is no inconsiderable part of the whole undertaking. It is hoped that in time the printing and illustrating will be done in a plant under the control of the Institution. The regular publications of the Institution will be in two forms, i.e., memoirs-quarto, and papers-octavo. It is estimated that there will be on an average five thick quarto volumes for each group of islands visited. The reports on each group will be as complete as possible and will constitute a biological and ethnological survey of the group as a unit. Each subject dealt with will in every case be treated by a specialist.

The smaller octavo series is to receive the miscellaneous papers 
growing out of the exploration. In it will be published the result of minor investigations carried on in the various departments in the Institution.

When the survey of the entire region has been completed, it is proposed to call upon the world's leading specialists in each department to aid in co-ordinating the work done by the field observers and systematic workers in the various groups. Thus only can deductions and conclusions be supplied that will be in keeping with the monumental labor that must be expended in consummating a work of such heroic proportions.

In conclusion it may be added that a worthy exploration of the Pacific on the lines indicated in this synopsis is a work which without doubt, in the bulk of publications and outlay of labor involved, will easily double that so successfully accomplished by the famous Challenger Exploring Expedition around the world; that being the only previous undertaking that has in any way approached in importance the task of exploration outlined for the Pacific Scientific Institution. 





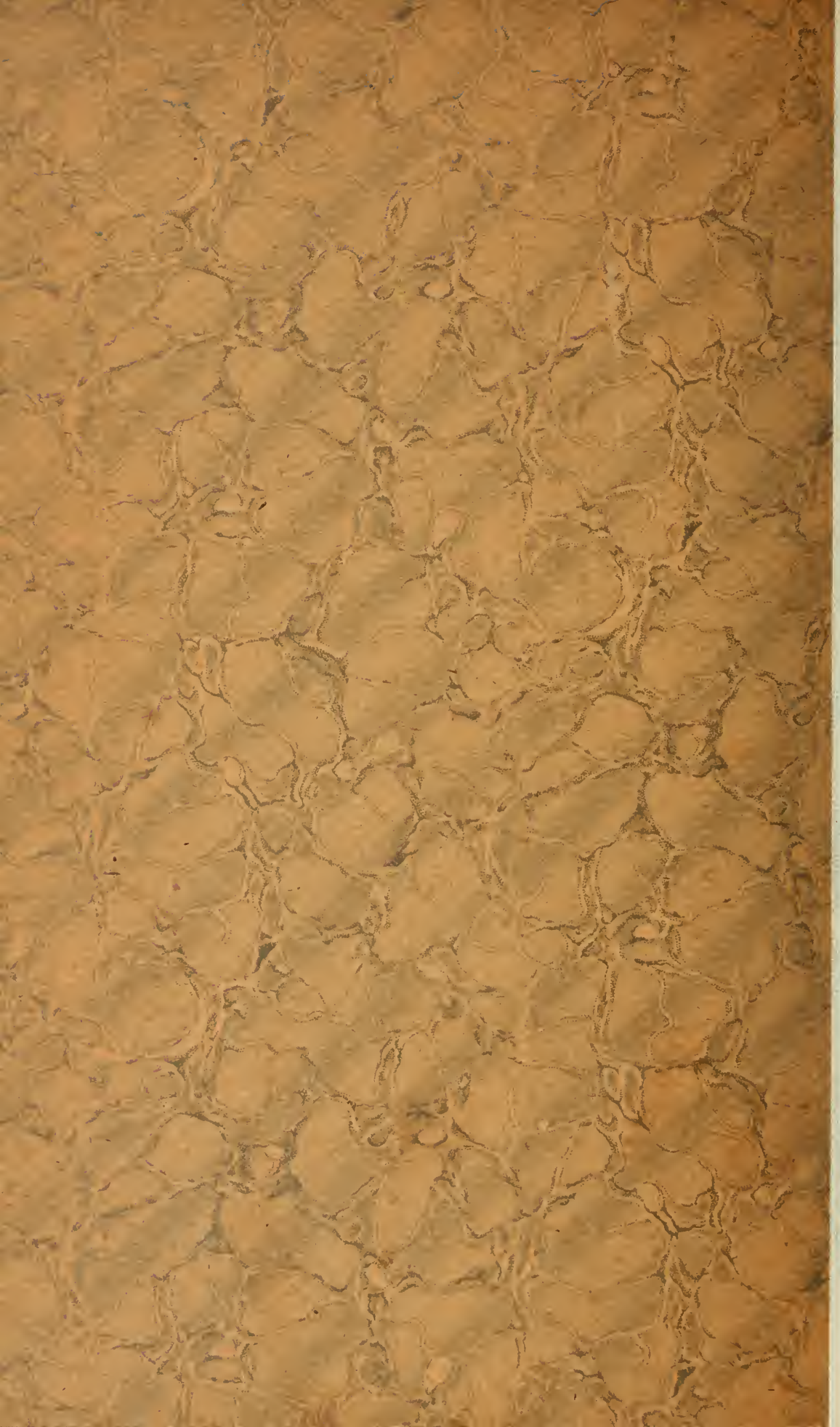

